\title{
A CENTRALIDADE DO DIREITO FUNDAMENTAL AO TRABALHO: UMA REFLEXÃO SOBRE O DIREITO AO TRABALHO E A VIRADA GE- STIONÁRIA NEOLIBERAL
}

Fernanda Demarco Frozza. Mestranda pelo Centro Universitário Autônomo do Brasil, UNIBRASIL, orientador Dr. Leonardo Wandelli. Especialista em Direito Constitucional pela Academia Brasileira de Direito Constitucional, ABDConst. Graduada em Direito pelas Faculdades Integradas Curitiba, UNICURITIBA. Integrante do Grupo de Pesquisa Trabalho Regulação no Estado Constitucional, GPTREC. fernandafrozza83@gmail.com ${ }^{1}$

\begin{abstract}
RESUMO
O presente estudo tem por objeto a reflexão sobre o conceito do direito ao conteúdo do próprio trabalho no atual contexto de precarização do trabalho, causado pelos novos métodos de gestão. O problema central da pesquisa é investigar as alterações introduzidas na organização do trabalho e os efeitos na subjetividade e saúde dos trabalhadores. Para tanto, se analisará o contexto neoliberal, a precariedade salarial e existencial e os novos métodos de gestão empregados na organização laboral, e as contribuições da psicodinâmica do trabalho quanto à centralidade do trabalho para a autorrealização e emancipação da subjetividade individual e coletiva, e possibilidade de ação política dos trabalhadores. Após, se analisará o direito fundamental ao conteúdo do próprio trabalho. E por fim, se afirmará a centralidade do direito fundamental ao trabalho para a realização dos demais direitos fundamentais do ser humano, sendo indispensável ao desenvolvimento de sua personalidade, identidade, autonomia, ao seu aprendizado moral, social e político, sendo importante que a dogmática jurídica assim o defenda.
\end{abstract}

Palavras-Chave: Centralidade do direito fundamental ao trabalho. Métodos de gestão. Psicodinâmica do trabalho.

\section{RESUMEN}

El propósito de este estudio es reflexionar sobre el concepto de derecho a los contenidos de su trabajo en el contexto actual de la precariedad del trabajo, causada por nuevos métodos de gestión. El problema central de la investigación es analizar los cambios en la organización del trabajo y los efectos en la subjetividad y la salud de los trabajadores. Por lo tanto, se examinará el contexto neoliberal, los salarios y la precariedad existencial y nuevos métodos de gestión empleados en la organización del trabajo, y las contribuciones de psicodinámica del trabajo con respecto a la centralidad del trabajo para la autorrealización y la emancipación de la subjetividad individual y colectiva, y la posibilidad la acción política de los trabajadores. Después, se examinará el derecho fundamental al contenido de la obra misma. Por último, se hará valer la centralidad del derecho fundamental al trabajo para la realización de otros derechos fundamentales de los

\footnotetext{
${ }^{1}$ http://lattes.cnpq.br/8470598747367087
} 


\section{SEMINÁRIO DE PESQUISA EM CIÊNCIAS HUMANAS - SEPECH \\ Humanidades, Estado e desafios didático-científicos \\ Londrina, 27 a 29 de julho de 2016}

seres humanos, es esencial para el desarrollo de su personalidad, la identidad, la autonomía, el aprendizaje moral, social y política, es importante que la dogmática legal para defenderse.

Palabras Clave: La centralización del derecho fundamental al trabajo. métodos de gestión. Psicodinámica del trabajo.

\section{INTRODUÇÃO}

O presente artigo propõem uma reflexão sobre os novos métodos de gestão empreendidos na organização do trabalho, no atual contexto neoliberal, e suas implicações no direito ao trabalho.

Parte-se da observação das mudanças efetivadas no ambiente do trabalho, em especial quanto à introdução da avaliação individual de desempenho, que acirra a competição entre os trabalhadores e estimula a competição, o que têm propiciado a precarização existencial e o aumento do adoecimento laboral, e que não significa necessariamente ganho salarial.

Com fundamento nos estudos da psicodinâmica do trabalho apresenta-se o trabalho como meio para o desenvolvimento da personalidade, da corporalidade e da identidade, bem como de laços de solidariedade e cooperação, e como espaço para a ação política na medida em que os trabalhadores discutem e decidem as regras que tornam o trabalho real. E por isso é meio para a emancipação e realização do indivíduo e da sociedade.

E então se expõe o conceito de direito ao conteúdo do próprio trabalho, que se traduz no direito a se desenvolver política, social e moralmente por meio do trabalho, independentemente do sistema econômico vigente. $\mathrm{O}$ trabalho é o meio pelo qual os indivíduos sobrevivem e se reproduzem, a medida que se desenvolvem, se realizam, se libertam e se emancipam nas diversas dimensões do humano.

Amparado nesta compreensão sobre o trabalhar, apresenta-se o entendimento de que o trabalho é o principal direito fundamental para a realização dos outros direitos fundamentais do ser humano. Isto possibilita afirmar a centralidade do direito fundamental ao trabalho para a realização da dignidade da pessoa humana. E por tal importância, entende-se que a dogmática jurídica deve construir estratégias formais e materiais em defesa do direito ao trabalho, dando-lhe força normativa, como instrumento de luta contra a precarização neoliberal.

Por fim, conclui-se que a efetivação dos direitos fundamentais e da democracia, isto é, da ordem constitucional vigente, exige que os juristas e operadores do direito busquem alternativas para garantir a força normativa do direito ao trabalho, possibilitando a vida digna das pessoas. 


\section{SEMINÁRIO DE PESQUISA EM CIÊNCIAS HUMANAS - SEPECH \\ Humanidades, Estado e desafios didático-científicos \\ Londrina, 27 a 29 de julho de 2016}

\section{A CENTRALIDADE DO DIREITO FUNDAMENTAL AO TRABALHO}

\subsection{Virada gestionária e neoliberalismo}

A análise se inicia com o olhar sobre a organização do trabalho no atual contexto de reestruturação produtiva, ou neoliberalismo, e quais são as repercussões no direito fundamental ao trabalho.

A reestruturação produtiva é entendida como a resposta dada a partir da década de 1990, pelo capital à sua crise iniciada nos anos 70, visando alternativas que conferissem maior dinamismo ao processo produtivo, que então dava sinais de esgotamento.

Como resposta à crise, deu-se início um processo de reorganização do capital e do seu sistema político e ideológico de dominação, “cujos contornos mais evidentes foram o advento do neoliberalismo, com a privatização do Estado, a desregulamentação dos direitos do trabalho e a desmontagem do setor produtivo estatal". (ANTUNES, 2009, 33).

O capitalismo viu-se frente a um quadro crítico acentuado, no qual "ocorreram mutações intensas, econômicas, sociais, políticas, ideológicas, com fortes repercussões no ideário, na subjetividade e nos valores constitutivos da classe-que-vive-do-trabalho, mutações de ordens diversas e que, no seu conjunto, tiveram forte impacto". A crise estrutural fez com que se implementasse um amplo processo de reestruturação do capital, visando recuperar o seu ciclo reprodutivo, afetando intensamente o mundo do traba1ho. "Embora a crise estrutural do capital tivesse determinações mais profundas, a resposta capitalista a essa crise procurou enfrentá-la tão-somente na sua superfície, na sua dimensão fenomênica, isto é, reestruturá-la sem transformar os pilares essenciais ao modo de produção capitalista (ANTUNES, 2003, p. 35-36).

A ofensiva neoliberal e a mundialização financeira do capital, a partir dos anos 1970, mostram aos países imperialistas que o sonho de um impulso progressista universal, dirigido por uma burocracia de Estado tecnicamente habilitada, visando o bem-estar social acabou, bem como o capitalismo aumentou as desiguladades (BRAGA, 2006, p. $1)$.

Para compreender objetivamente os problemas da cotidianidade se faz necessário considerar a subjetividade, a qual está sendo degradada pelo capitalismo, mas que tem potencial emancipador por meio do trabalho, cuja potencialidade é a transformação social (ALMADA, 2015, p. 379).

Portanto, entende-se que as mudanças realizadas no neoliberalismo afetam a subjetividade do trabalhador de maneira mais intensa, o que tem contribuído para a precarização do trabalho, e ameaçado reduzir os direitos fundamentais sociais dele decorrentes, e conquistados pelos trabalhadores ao longo dos Séculos XIX e XX.

Em entrevista ao jornal português "Público", Christophe Dejours responde que o que mudou nas empresas foi:

A organização do trabalho. Para nós, clínicos, o que mudou foram principalmente três coisas: a introdução de novos métodos de avaliação do trabalho, em particular a avaliação individual do desempenho; a introdução de técnicas ligadas à chamada "qualidade total"; e o outsourcing, que tornou o trabalho mais precário. A avaliação individual é uma técnica extremamente poderosa que modificou totalmente o mundo do tra 


\section{SEMINÁRIO DE PESQUISA EM CIÊNCIAS HUMANAS - SEPECH \\ Humanidades, Estado e desafios didático-científicos \\ Londrina, 27 a 29 de julho de 2016}

balho, porque pôs em concorrência os serviços, as empresas, as sucursais - e também os indivíduos. E se estiver associada quer a prémios ou promoções, quer a ameaças em relação à manutenção do emprego, isso gera o medo. E como as pessoas estão agora a competir entre elas, o êxito dos colegas constitui uma ameaça, altera profundamente as relações no trabalho: "O que quero é que os outros não consigam fazer bem o seu trabalho". Muito rapidamente, as pessoas aprendem a sonegar informação, a fazer circular boatos e, aos poucos, todos os elos que existiam até aí - a atenção aos outros, a consideração, a ajuda mútua - acabam por ser destruídos. As pessoas já não se falam, já não olham umas para as outras. E quando uma delas é vítima de uma injustiça, quando é escolhida como alvo de um assédio, ninguém se mexe... (2010, p. 3).

A gestão de desempenho integra um processo maior de gestão organizacional, permitindo rever objetivos, estratégias, processos de trabalho e políticas de recursos humanos, com o objetivo de corrigir desvios e ressignificar a continuidade e sustentabilidade da organização, e proporciona o controle psicossocial dos trabalhadores. (BRANDÃO e GUIMARÃES, 2001, p. 12).

Esta avaliação não considera o real do trabalho, quer dizer, a mobilização do zelo e da cooperação, o empenho, o sofrimento, a renúncia dedicados pelo trabalhador. Não recai sobre trabalho, mas apenas sobre o seu resultado. As avaliações, mesmo que coletivas, negam reconhecimento ao trabalho real, desativando, geralmente, os mecanismos de reconhecimento de beleza pelos colegas, o que corta o vínculo ético com o trabalho bem feito e não permite que o sujeito se reconheça e seja reconhecido pelo seu trabalho, de maneira positiva, o que gera graves efeitos à saúde mental (WANDELLI, 2012, p. 200-201).

O efeito principal da avaliação individual de desempenho é introduzir o princípio de competição entre os trabalhadores, os serviços, as instituições, as filiais, deteriorando as regras de bem viver, pois acompanhada de ameaças veladas ou expressas, destruindo vínculos de respeito, confiança e solidariedade, dos quais dependem a cooperação e o trabalho coletivo. E ainda, quebrar os padrões éticos que o trabalhador possui, aumenta ainda mais o seu sofrimento, fazendo com que as suas estratégias defensivas cedam lugar às práticas de violência no trabalho, o que resulta em isolamento e desolação, podendo levar ao suicídio (WANDELLI, 2012, p. 201).

Portanto, as mudanças sócio-econômicas ocorridas a partir dos anos 1990 recebem aqui o nome de reestruturação produtiva e correspondem ao período histórico denominado de neoliberalismo, traduzindo-se na sujeição mais intensificada do trabalhador aos interesses do capital. Isso se dá na medida em que o sujeito deve mobilizar cada vez mais a sua subjetividade para se adaptar às novas formas de gestão aplicadas no trabalho e às inovações trazidas pelas tecnologias, que tornam o trabalho acessível ao trabalhador vinte e quatro horas por dia, sete dias na semana. Isso, aliado à redução de direitos sociais, tem implicado na atual precarização do trabalho.

Porém, o trabalho é meio para a transformação do humano, da coletividade e do mundo, devendo ser tutelado pelo Direito como fundamental à autorrealização e emancipação da pessoa humana. 


\section{SEMINÁRIO DE PESQUISA EM CIÊNCIAS HUMANAS - SEPECH \\ Humanidades, Estado e desafios didático-científicos \\ Londrina, 27 a 29 de julho de 2016}

\section{O TRABALHO COMO MEIO DE EMANCIPAÇÃO E REALIZAÇÃO INDI- VIDUAL E COLETIVA A PARTIR DA PSICODINÂMICA DO TRABALHO}

A noção clínica, apresentada pela psicodinâmica do trabalho, entende que "trabalhar é engajar sua subjetividade num mundo hierarquizado, ordenado e coercitivo, perpassado pela luta da dominação". Para que o processo de trabalho funcione, se faz necessário "reajustar as prescrições e afinar a organização efetiva do trabalho, diferente da organização prescrita". Para atingir este resultado, supõe-se que cada trabalhador se envolva, individualmente, "no debate coletivo para nele dar testemunho de sua experiência, esforçando-se para tornar visíveis e inteligíveis suas contribuições, seu saberfazer, suas habilidades, seus modos operatórios" (DEJOURS, 2004, p. 31-32).

Este mecanismo faz com que os acordos firmados entre os trabalhadores - por meio da atividade deôntica - tenham uma dupla vetorização: de uma parte, um objetivo de qualidade e eficácia no trabalho; de outra, um objetivo social. A cooperação supõe um compromisso que é ao mesmo tempo técnico e social (DEJOURS, 2004, p. 32).

O trabalhador, dada a pressão organizacional, se vê num dilema: é preciso transgredir para poder trabalhar, do contrário, ele ficaria paralisado, o que também não pode acontecer. (HELOANI e SILVA, 2014, p. 106). Trabalhar é ter que lidar com a impossibilidade de cumprimento das prescrições dadas e o sofrimento experienciado pelo sujeito, que entre fatores de hierarquia e dominação social, tem que articular a sua subjetividade - desenvolvendo a sua personalidade, corporalidade e identidade - para encontrar soluções com os demais trabalhadores envolvidos. E esta mobilização da inteligência psíquica é entendida como trabalho não mensurável.

O trabalho, portanto, contém uma dimensão subjetiva, intelectual, invisível e impossível de ser medida e avaliada objetivamente - o que é desconsiderado pelos métodos de gestão neoliberais - sendo reconhecido pelos pares, colegas de trabalho, a partir de uma dimensão qualitativa, passando pelo julgamento de beleza, que propõem duas dimensões: a conformidade com as regras e a simplicidade da execução, da feitura e o caráter despojado das soluções propostas (DEJOURS, 2012, p. 54-55).

De um lado o mundo do trabalho gera sofrimento, na medida em que confronta as pessoas com desafios externos, mas de outro lado, é a oportunidade central de crescimento e de desenvolvimento psicossocial do adulto. $\mathrm{O}$ trabalho que leva ao sofrimento e ao adoecimento, é o mesmo trabalho que pode se constituir em fonte de prazer e desenvolvimento humano do indivíduo. Assim, fica claro que o trabalho e as relações que nele se originam não podem ser tomadas como espaço de neutralidade social e subjetiva. (HELOANI e LANCMAN, 2004, p. 78).

Assim, é possível entender que ao trabalhar o sujeito se depara com o real, sentindo-o como fracasso, o que proporciona a busca interna e desenvolvimento de recursos psíquicos para lidar com o real. Este movimento psíquico é considerado trabalho, pois é a exigência de trabalho psíquico para que o sujeito desenvolva habilidades profissionais.

Este engajamento da subjetividade na confrontação à resistência do real pode fazer advir novos registros de sensibilidade, que não estavam presentes no $\mathrm{Eu}$ antes da experiência do real e da perseverança no esforço diante da resistência do real e do sofrimento decorrente. E assim o trabalho permite uma ampliação da subjetividade, a medida que essas novas sensibilidades se revelam à sensibilidade por meio do trabalho e da experiência por ele produzida (DEJOURS, 2012, p. 84). 


\section{SEMINÁRIO DE PESQUISA EM CIÊNCIAS HUMANAS - SEPECH \\ Humanidades, Estado e desafios didático-científicos \\ Londrina, 27 a 29 de julho de 2016}

Assim, compreende-se que ao trabalhar, o sujeito precisa buscar, em sua psique, recursos para lidar com o real, desenvolvendo novas habilidades profissionais, o que altera e constrói a sua personalidade, consequentemente, o trabalhador se desenvolve enquanto ser humano. E portanto, entende-se que o Direito deve tutelar esta dimensão antropológica do trabalho, viabilizando que a pessoa humana alcance a sua dignidade por meio do trabalho.

Ainda, o trabalho desenvolvido sob uma organização saudável permite que os trabalhadores construam coletivamente uma obra comum - ação coletiva - por meio da participação democrática dos envolvidos nas escolhas dos procedimentos que serão adotados na consecução do trabalho, o que origina a ação política e é denominada de atividade deôntica.

A ação coletiva é racional conforme ela se dá pela luta contra a injustiça e, a ação política, por consequência é a celebração da vida e não o culto ao poder, o "gozo do poder" ou a "promoção do individualismo consumista". Uma ação é racional apenas se considerar o destino da subjetividade no trabalho e se ela, ao mesmo tempo, se alimentar daquilo que provém da subjetividade. (DEJOURS, 2004, p. 33).

Portanto, o trabalho - além de conter o caráter de sofrimento - apresenta-se como forma de o sujeito utilizar-se de sua inteligência e corporalidade, para coletivamente e em cooperação - o que exige reprimir parte de sua subjetividade e aceitar parte da subjetividade dos colegas - participar da ação política em busca do melhor, em busca de uma obra coletiva. Pensar a relação trabalho, subjetividade e ação é verificar o caráter democrático que o trabalho possui.

E sob este fundamento do trabalho como mediador para a construção da subjetividade, personalidade e identidade da pessoa, que viabiliza a autorrealização e emancipação política, moral/ética e social do ser humano, que se afirma a centralidade do direito fundamental ao trabalho para a dignidade da pessoa humana.

\section{O CONCEITO DE DIREITO AO CONTEÚDO DO PRÓPRIO TRABALHO}

É necessário considerar que o trabalho é capaz de gerar o melhor, enquanto mediador insubstituível para a autonomia, a saúde, a aprendizagem moral e política e para a emancipação do humano, e não só capaz de causar o pior, em termos de alienação, degradação da saúde e reprodução de práticas sociais de violência. Em razão dessa dialética do trabalho, as considerações provenientes da metapsicologia dejouriana, podem ser fundamentais, ao tomarem o trabalho como mediador privilegiado da estruturação da subjetividade e do aprendizado da convivência. "Não basta proteger as pessoas dos possíveis efeitos deletérios do trabalho, é preciso assegurar as condições pelas quais o trabalho pode desempenhar seu papel constitutivo para o sujeito" (WANDELLI, 2012, p. 64).

E isso permite que se afirme o trabalho como o direito fundamental central para a concretização dos demais direitos fundamentais. Ele é o fundamento para o conteúdo dos diversos direitos referidos nos arts. $7^{\circ}$ a 11 da Constituição, que são desdobramentos parciais do direito fundamental ao trabalho referido no art. $6^{\circ}$ (WANDELLI, 2012, p. 224).

Portanto, o direito fundamental ao trabalho merece maior proteção dogmática pelos juristas. Trata-se de saber até que ponto se pode tomar seriamente a compreensão 


\section{SEMINÁRIO DE PESQUISA EM CIÊNCIAS HUMANAS - SEPECH \\ Humanidades, Estado e desafios didático-científicos \\ Londrina, 27 a 29 de julho de 2016}

constitucional de que o fundamento maior do direito é a dignidade da pessoa humana perante a cultura, o direito, as instituições, o mercado e não o inverso (WANDELLI, 2014, p. 1019).

A valorização social do trabalho prevalece sobre a livre-iniciativa como razão de ser de um ordenamento Constitucional, que serve de mediação institucional para a produção, a reprodução e o desenvolvimento da vida concreta das pessoas. Se existir tensão entre esses valores, é a livre-iniciativa que deve se adaptar aos limites impostos pela preservação da dignidade do trabalho vivo, cujos conteúdos e limites materiais inerentes à vida humana se sobrepõem ao caráter carente e contingente de transformação de uma forma de organização social específica. (WANDELLI, 2012, p. 228).

Portanto, na relação trabalho-capital, o Direito deve tutelar a pessoa humana, fazendo com que as instituições, livre-iniciativa, mercado e capital se adaptem às normas que protegem o trabalhador. E o jurista é responsável por esta defesa.

Para se dar coerência à ordem constitucional vigente, é necessário reconhecer a força normativa ${ }^{2}$ real do direito fundamental ao trabalho, especialmente quando em conflito com outros comandos legais. (WANDELLI, 2012, p. 292).

O direito ao conteúdo do próprio trabalho refere-se a uma ocupação efetiva qualificada que expressa o direito a que o trabalho concretamente realizado seja uma via possível de desenvolvimento da personalidade do trabalhador, na qual possa aplicar suas aptidões físicas e mentais em condições que, não só, excluam fatores nocivos de segurança, salubridade e desgaste excessivo, mas também que incluam elementos de conteúdo significativo da atividade e dos processos de trabalho, bem como condições do ambiente organizacional necessárias a que se possam desenvolver os processos deliberativos e de colaboração, reconhecer-se e ver reconhecida sua contribuição singular para a coletividade por meio do trabalho bem feito e da participação na obra comum (WANDELLI, 2012, p. 296).

Compreender este conteúdo do direito ao trabalho proporciona entender que aquele que trabalha, não só o faz para outrem, mas o faz para si, consigo e com outrem. E esta nova compreensão do trabalho enquanto necessário à vida e à dignidade da pessoa humana, gera novos efeitos pessoais, sociais e políticos, que são amparados constitucionalmente, sendo tutelados por meio do direito - formal e materialmente - fundamental ao trabalho, o que vincula Estado e particulares, aos deveres de respeito, proteção e implementação, consequentemente pautando as políticas públicas inerentes ao direito ao trabalho (WANDELLI, 2012, p. 295).

Assim, a partir da noção de que o trabalho é o meio pelo qual o homem altera a si mesmo, o outro e a natureza, garante a sua subsistência, atua na vida social, por meio da construção coletiva, se autorrealiza e emancipa, pode-se afirmar que o direito ao trabalho é o direito fundamental - central - para que o homem conquiste os demais direitos humanos e, consequentemente, a sua dignidade.

\footnotetext{
${ }^{2}$ Konrad Hesse ensina que a força normativa da Constituição se traduz na consciência geral - particularmente, na consciência dos principais responsáveis pela ordem constitucional -, não só a vontade de poder (Wille zur Macht), mas também a vontade de Constituição (Wille zur Verfassung). (1991. p. 19).
} 


\section{SEMINÁRIO DE PESQUISA EM CIÊNCIAS HUMANAS - SEPECH \\ Humanidades, Estado e desafios didático-científicos \\ Londrina, 27 a 29 de julho de 2016}

Portanto, entende-se que a efetivação da democracia e dos direitos fundamentais exige a afirmação do direito constitucional fundamental ao trabalho, enquanto direito central para a concretização da dignidade da pessoa humana, devendo ser respeitado e garantido pelo Estado e pela sociedade civil, a partir de ações e políticas públicas que visam garantir a sua força normativa.

\section{CONCLUSÃO}

É possível compreender, baseado no referencial teórico aqui exposto, que o sentido do trabalho está sendo reduzido a um bem necessário, um meio de sobrevivência ou de adquirir bens de consumo. Porém, o trabalho é muito mais do que isso. Em sua dimensão antropológica, de alterar a natureza e a si mesmo, constitui o ser humano e constrói a sociedade, existindo independentemente do sistema econômico vigente.

Trabalhar é também uma fonte de prazer, a medida que é uma maneira do ser humano se conhecer, se disciplinar, desenvolver novas formas de atuar no mundo, de aprender e criar regras de sociabilidade, se superar, desenvolver seu potencial criativo e crítico, e com isso se realizar e se emancipar.

O trabalho possibilita desenvolvimento individual, pois permite que as pessoas não só sobrevivam, mas também se auto determinem, vivendo de acordo com as escolhas que lhe são possíveis dentro de determinado contexto cultural, econômico e social, e é também meio que garante a reprodução da vida humana.

O trabalho é espaço para a ação política também, vez que viabiliza que os trabalhadores possam experienciar o real do trabalho coletivamente, mobilizando as suas inteligências para vencer os desafios da realidade e tornar possível o produto do traba1ho. Para que isso ocorra cada um dos envolvidos deve expor parte da sua personalidade, reprimir outra parte, e aceitar parte da dos colegas, para que democraticamente se construa uma obra comum. E isso demanda o aprendizado da confiança, cooperação, solidariedade.

Porém, os métodos de gestão empreendidos na contemporaneidade, em particular a avaliação individual de desempenho, estão incentivando o individualismo e a competição e descontruindo as possibilidades da cooperação e da solidariedade. E com isso o real do trabalho para a subjetividade deixa de ser dividido entre os trabalhadores, gerando solidão e adoecimento.

Assim, entende-se que a organização do trabalho neoliberal ofende o direito fundamental ao trabalho, consequentemente ameaça o desenvolvimento saudável da personalidade do sujeito e a dignidade da pessoa humana, causando prejuízo ao indivíduo e à sociedade.

A compreensão do direito ao trabalho como direito central para a realização dos demais direitos fundamentais permite conceber que trabalhar é uma necessidade para a concretização das necessidades materiais, mas também intelectuais e espirituais do ser humano, implicando em maior responsabilidade de defesa e promoção por parte do Estado e da sociedade civil.

A partir do conceito de conteúdo ao próprio trabalho se quer sensibilizar a dimensão emancipatória do trabalho, que pode proporcionar desenvolvimento do sujeito, da política e da sociedade, construindo-se um pensamento axiológico condizente com a 


\section{SEMINÁRIO DE PESQUISA EM CIÊNCIAS HUMANAS - SEPECH \\ Humanidades, Estado e desafios didático-científicos \\ Londrina, 27 a 29 de julho de 2016}

teoria dos direitos fundamentais, que é a base da Constituição, em Estados Democráti$\cos$.

Assim, afirma-se que o Direito tem a função de criar estratégias dogmáticas para, formal e materialmente, defender a centralidade do direito humano e fundamental ao trabalho, para, além de mecanismos combativos à precarização neoliberal, garantir a vida, e a vida humana digna.

\section{REFERÊNCIAS BIBLIOGRÁFICAS}

ALMADA, Pablo. O resgate da ontologia: os limites da "transição paradigmática" e a necessidade de retomada da ontologia social. In: BESTER, G.M., COSTA, H.A., HILÁRIO, G.M.A. Ensaios de Direito e de Sociologia a partir do Brasil e de Portugal: movimentos, direitos e instituições. Gisela Maria Bester, Hermes Augusto Costa, Gloriete Marques Alves Hilário (cordenadores). Gisela Maria Bester, Hermes Augusto Costa (organizadores). $1^{\text {a }}$ edição. Curitiba: Instituto memória Editora. Centro de Estudos da Contemporaneidade, 2015. p. 352-380.

ANTUNES, Ricardo. Os sentidos do trabalho. Ensaios sobre a afirmação e a negação do trabalho. Boitempo Editorial. 2003.

Os sentidos do trabalho. Ensaios sobre a afirmação e a negação do trabalho. Boitempo Editorial. 2009.

BRAGA, Ruy. Infotaylorismo: o trabalho do teleoperador e a degradação da relação de serviço. In: Revista de economía política de las tecnologías de la información y comunicación. www.eptic.com.br Vol. VIII, n.1. ene-abr 2006. Disponível em: $<$ http://seer.ufs.br/index.php/eptic/article/viewFile/291/270>. Acesso em 22/09/2015.

BRANDÃO, Hugo Pena. GUIMARÃES, Tomás de Aquino. Gestão de competências e gestão de desempenho: tecnologias distintas ou instrumentos de um mesmo construto? Rev. adm. empres. vol.41 no.1 São Paulo Jan./Mar. 2001. Disponível em: $<$ http://www.scielo.br/pdf/rae/v41n1/v41n1a02.pdf>. Acesso em 30/05/2016.

DEJOURS, Christophe. Psicodinâmica do trabalho: contribuições da escola dejouriana à análise prazer, sofrimento e trabalho. São Paulo: Editora Atlas S.A. 2012.

Um suicídio no local de trabalho é uma mensagem brutal. Disponível em $\overline{<\mathrm{https}}$ ://www.publico.pt/temas/jornal//um-suicidio-no-trabalho-e-uma-mensagembrutal-18695223>. Acesso em 02/03/2016.

Sexualidade e trabalho. Trabalho vivo, tomo I. Brasilia: Paralelo 15, 2012.

2004 .

Subjetividade, trabalho e ação. Revista Produção, v.14, n. 3, p. 27-34, set./dez. 


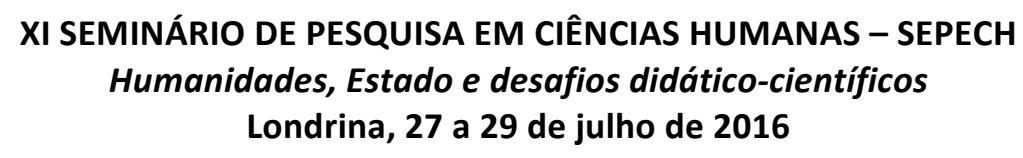

HELOANI, Roberto. SILVA, Eduardo Pinto e. Para além do julgamento: aspectos psicodinâmicos do trabalho do magistrado trabalhista. In: ALVES, Giovanni. O trabalho do juiz: Análise crítica do vídeo documentário O trabalho do juiz. Bauru: Canal 6, 2014.

HELOANI, Roberto. LANCMAN, Selma. Psicodinâmica do trabalho: o método clínico de intervenção e investigação. Revista Produção, v. 14, n. 3, p.77-86, set./dez. 2004. Disponível em <http://www.scielo.br/pdf/prod/v14n3/v14n3a08.pdf > Acesso em 09/04/2016.

HESSE, Konrad. A força normativa da Constituição. Porto Alegre: Sergio Antonio Fabris Editor.1991.

WANDELLI, Leonardo Vieira. O direito humano e fundamental ao trabalho: fundamentação e exigibilidade. São Paulo: LTr, 2012.

O direito fundamental ao trabalho na ordem na ordem jurídica brasileira. In: CLÈVE, Clèmerson Merli. Direito Constitucional Brasileiro: teoria da Constituição e direitos fundamentais. Vol.1. São Paulo: Editora Revista dos Tribunais. 2014. p. 9871022.

. Valor social do trabalho e dignidade na Constituição. In: CLEVE, Clemerson Merlin. Direito Constitucional Brasileiro: teoria da Constituição e direitos fundamentais. Sao Paulo: Editora Revista dos Tribunais, 2014. p. 245-264. 